\title{
Bio-inspired Incrustation Interfacial Polymerization of
}

\section{Dopamine and Crosslinking with Gelatin toward Robust, Biodegradable Three-dimensional Hydrogels}

\author{
AUTHOR NAMES \\ Hiroya Abe ${ }^{1,2 *}$ Hiroshi $\mathrm{Yabu}^{2,3}$
}

AUTHOR ADDRESS

1. Frontier Research Institute for Interdisciplinary Sciences (FRIS), Tohoku University, 6-3 Aramaki Aoba, Aoba-ku, Sendai 980-8578, Japan.

2. WPI-Advanced Institute for Materials Research (AIMR), Tohoku University, 2-1-1 Katahira, Aoba-ku, Sendai 980-8577, Japan

3. Institute of Multidisciplinary Research for Advanced Materials (IMRAM), Tohoku University, 2-1-1 Katahira, Aoba-ku, Sendai 980-8577, Japan

Corresponding Author: H. A., hiroya.abe.c4@tohoku.ac.jp 


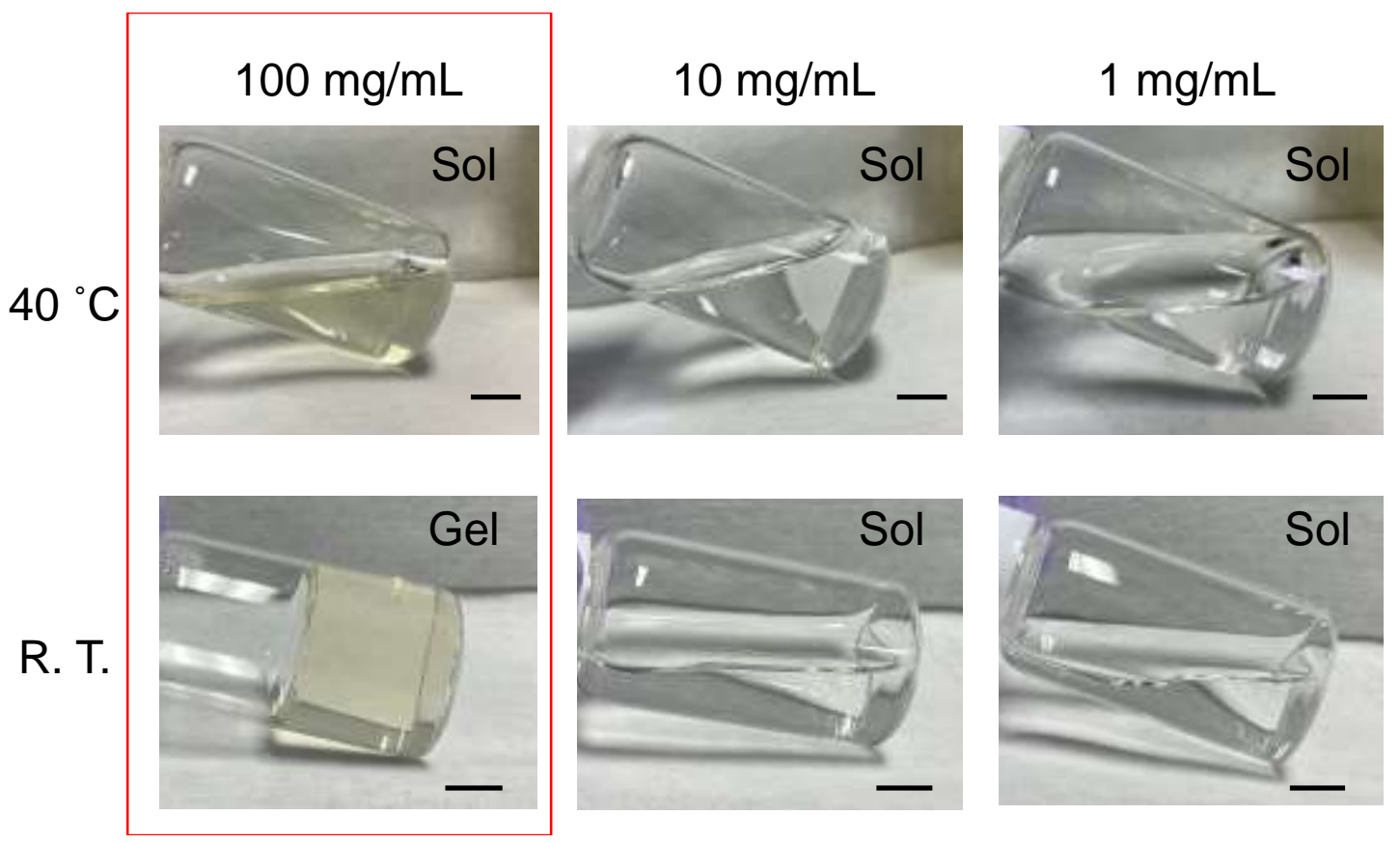

Figure S1. Sol-gel transformation for the gelatin solution at a different concentration of gelatin. Only $100 \mathrm{mg} / \mathrm{mL}$ gelatin solution showed the sol-gel transformation. All scale bars are $1 \mathrm{~cm}$. 
(a) $1: 10,30 \mathrm{~h}$

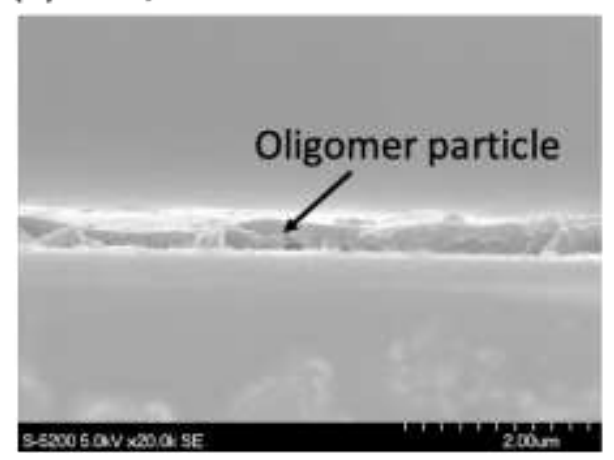

(a) $10: 10,30 \mathrm{~h}$

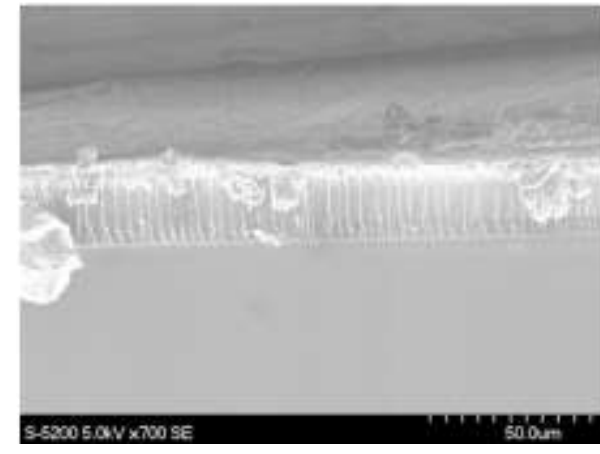

$1: 10,48 \mathrm{~h}$

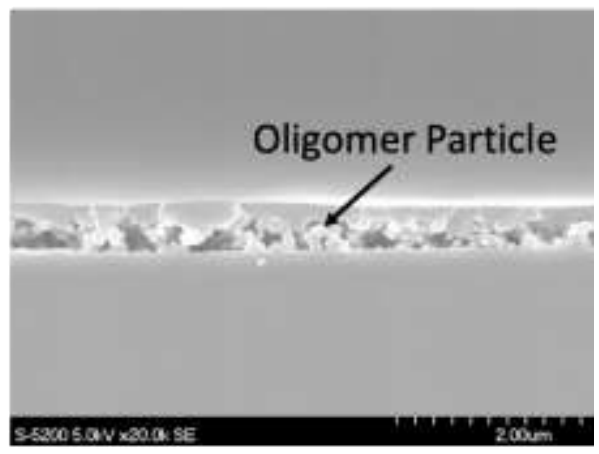

$10: 10,48 \mathrm{~h}$

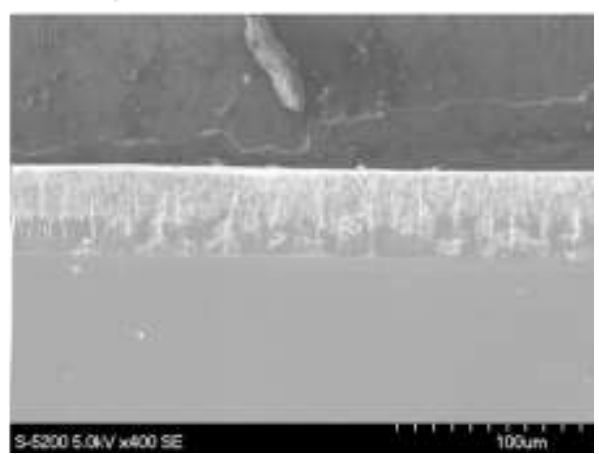

Figure S2. SEM images of GelDA for at different gelatin concentration; (a) 1:10 and (b) 10:10. Small particles were observed in the GelDA (1:10). 


\section{$100 \mathrm{mg} / \mathrm{mL}$ gelatin at $50{ }^{\circ} \mathrm{C}$}

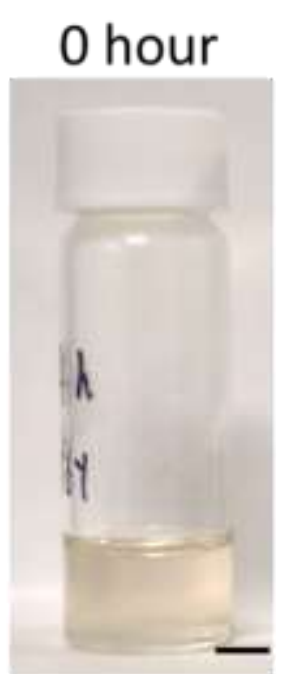

30 hours

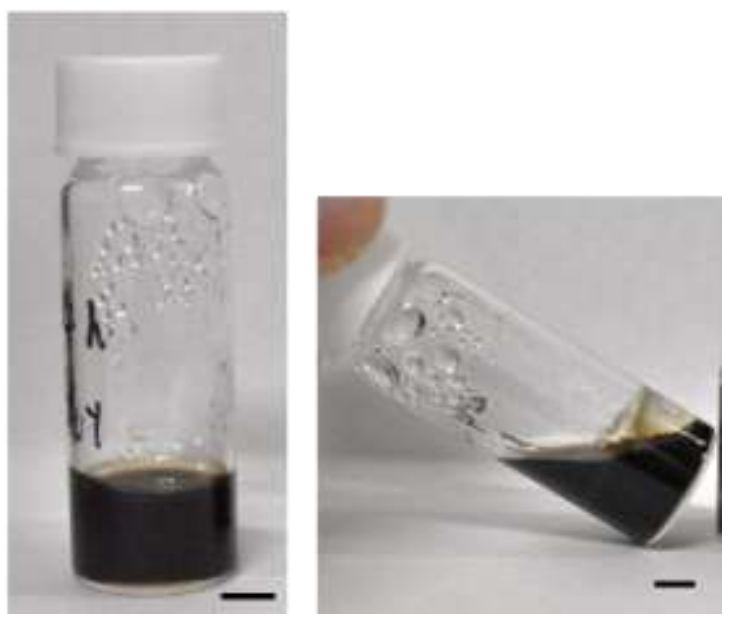

Figure S3. GelDA formation in the sol state. Scale bars: $5 \mathrm{~mm}$. 


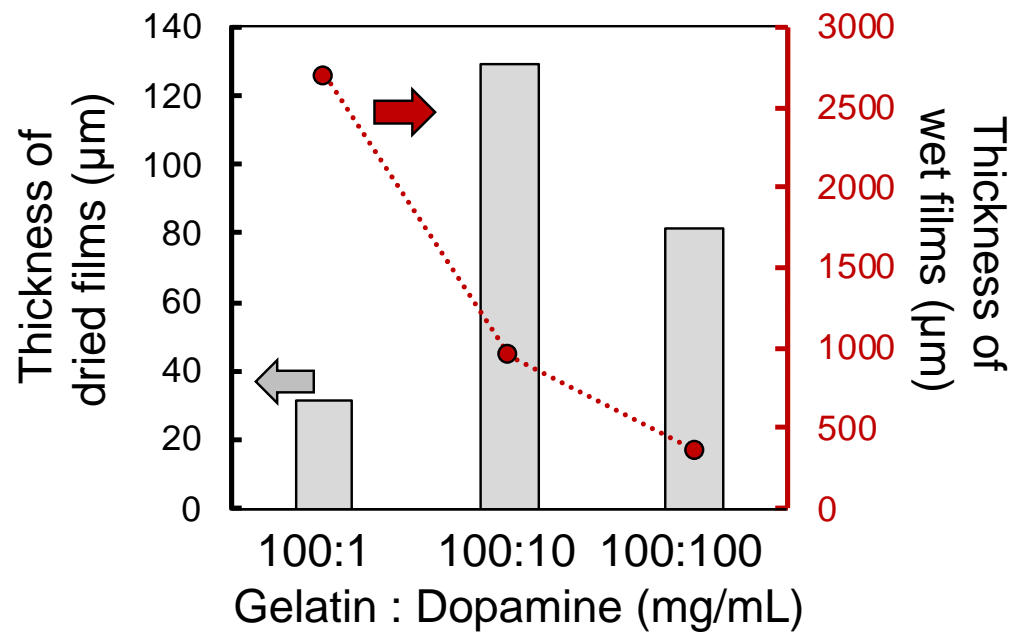

Figure S4. Changes of thickness at different concentrations of dopamine with a constant concentration of gelatin $(100 \mathrm{mg} / \mathrm{mL})$. The gray bars show the thickness of GelDA after drying. The red circles show the thickness of GelDA under the wet state. 


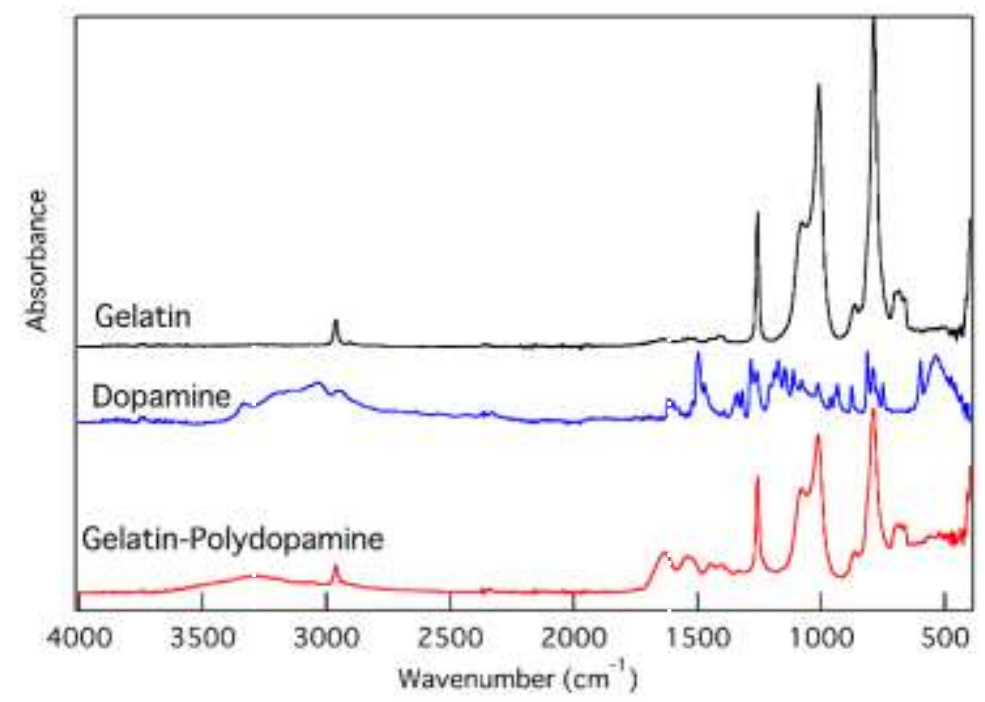

Figure S5. FT-IR spectra of gelatin (black), dopamine (blue) and GelDA (red). 


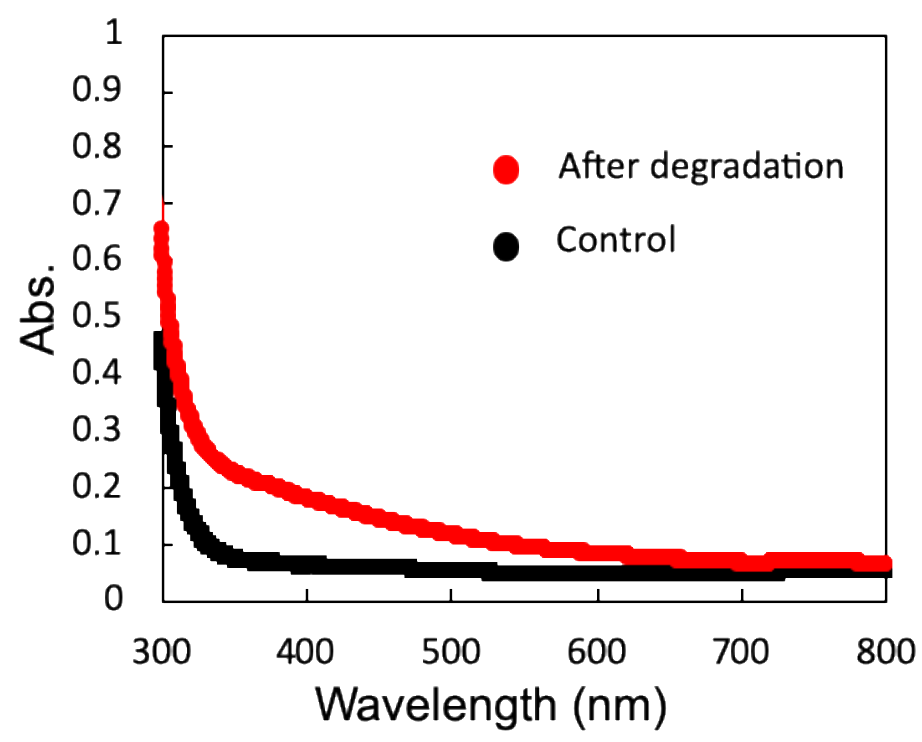

Figure S6. UV-vis spectra of GelDA dissolved in a $2 \mathrm{mg} / \mathrm{mL}$ collagenase solution (after degradation; red) and in a solution without collagenase (control; black). 


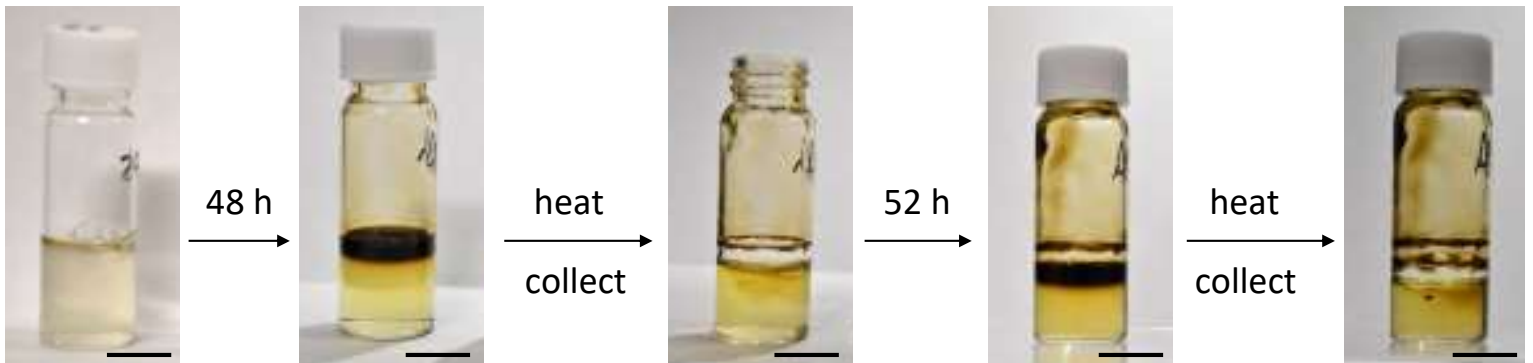

Figure S7. The shedding of GelDA at the air/gel interface. Scale bars: $1 \mathrm{~cm}$. 
Supporting Information

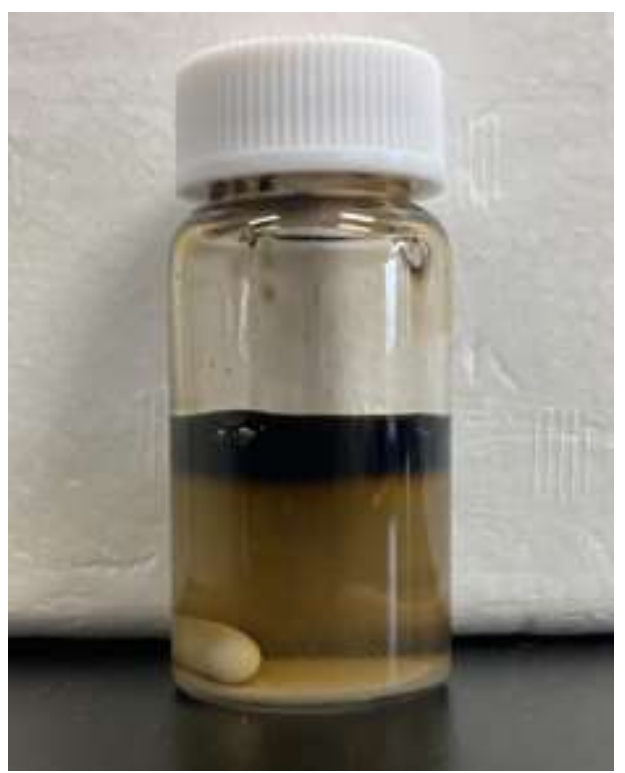

Figure S8. GelDOPA prepared from $100 \mathrm{mg} / \mathrm{mL}$ gelatin and $10 \mathrm{mg} / \mathrm{mL}$ L-DOPA after $48 \mathrm{~h}$. 


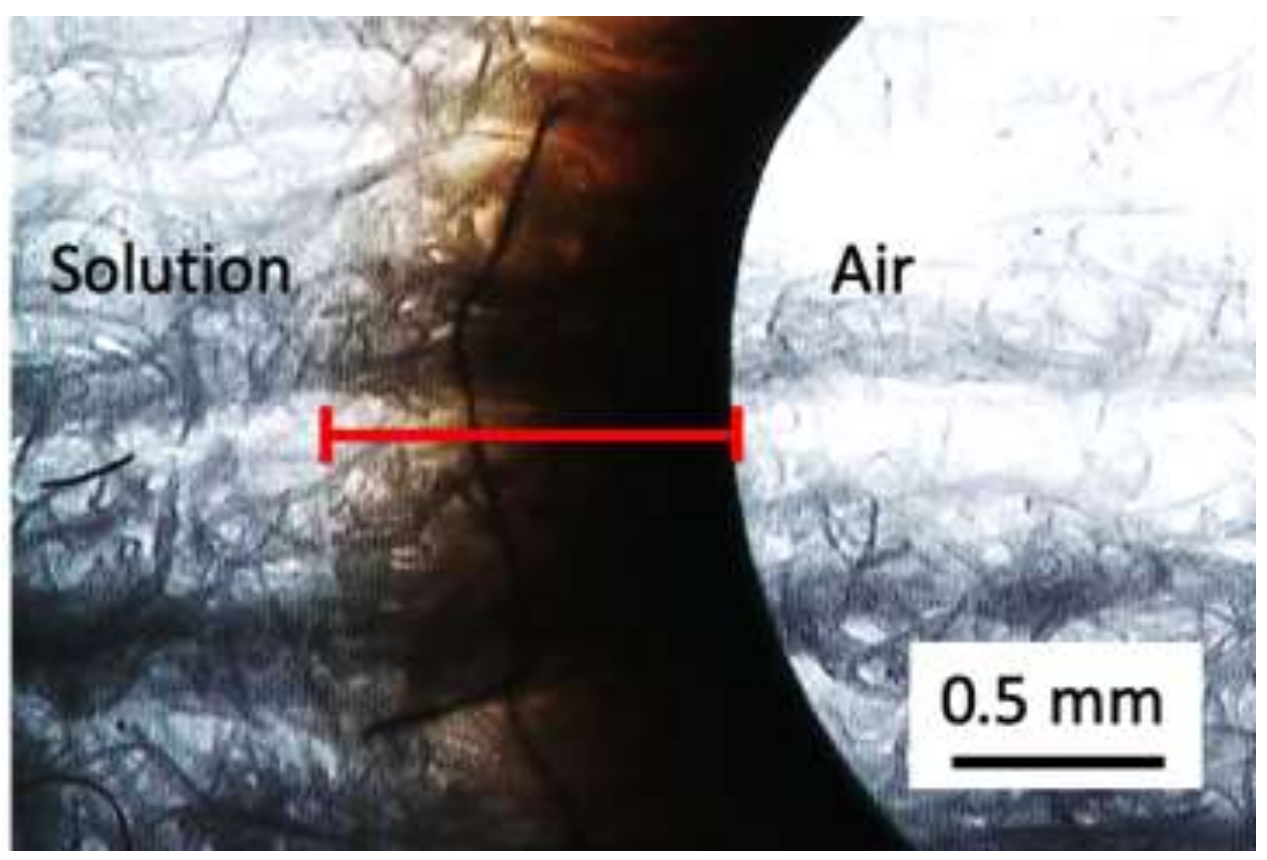

Figure S9. An optical microscope image of the cross-sectional GelDA film (100:10). 
(a)

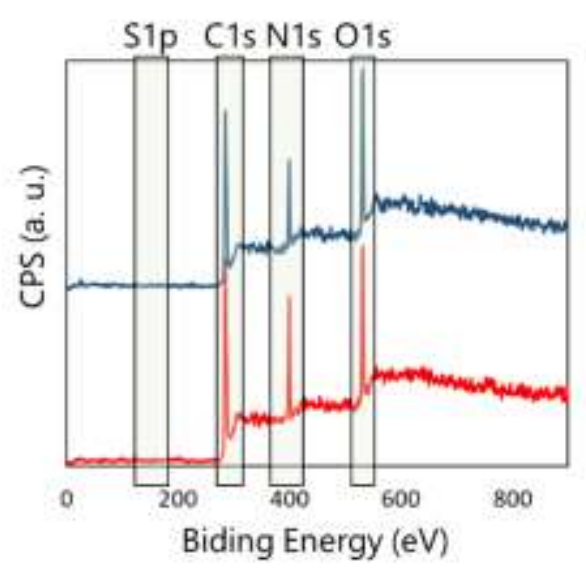

(b)
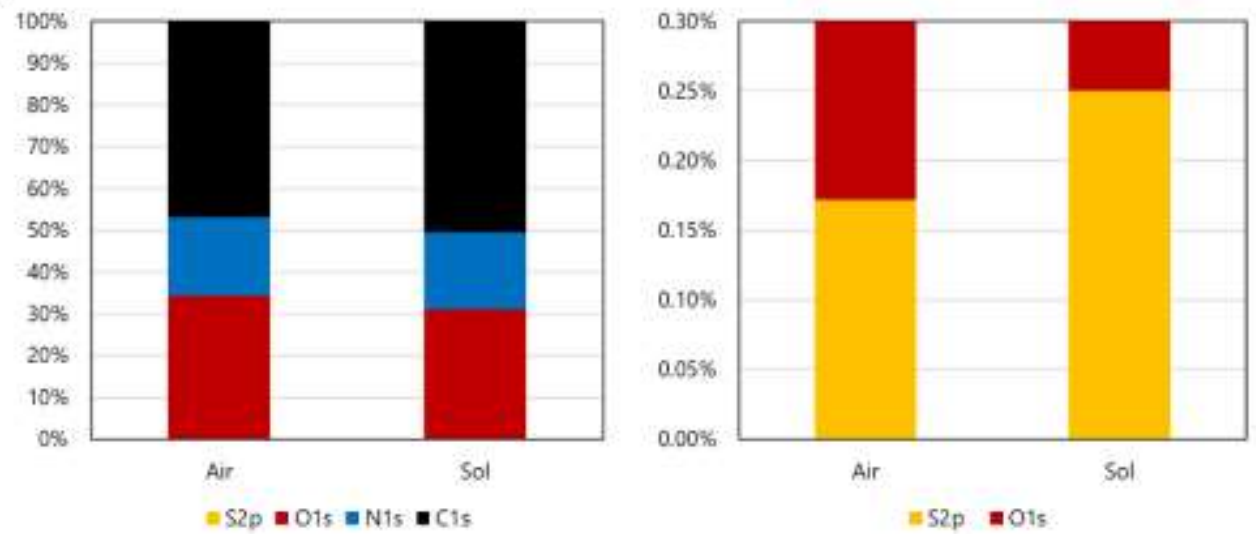

Figure S9. (a) Wide-scan XPS spectra of GelDA at air (blue) and solution (red) side. (b)

Amounts of elements for the GelDA at air and solution side, calculated from narrow-scan XPS spectra. 


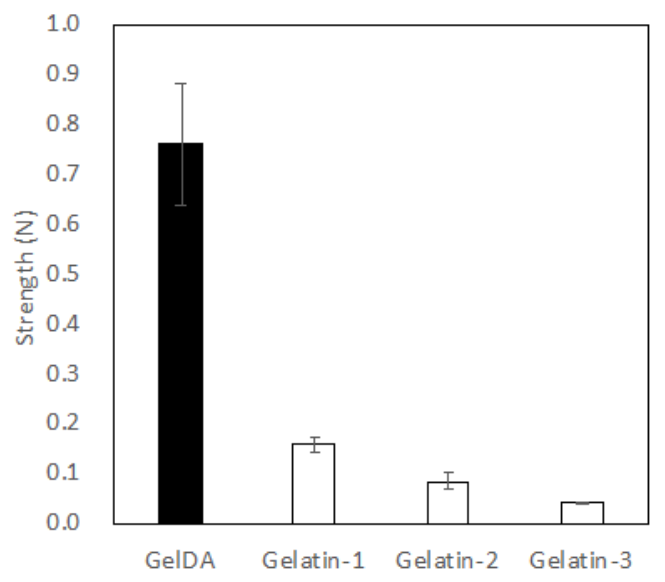

Figure S11. The mechanical strength measured by the tensile test of GelDA (thickness:

c.a. $0.8 \mathrm{~mm}$ ) and gelatin-1, -2 and -3 (thickness: c.a. $1.8,1.5$ and $1.0 \mathrm{~mm}$, respectively). 
(a)

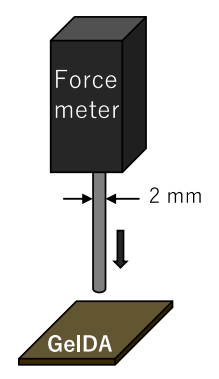

(b)

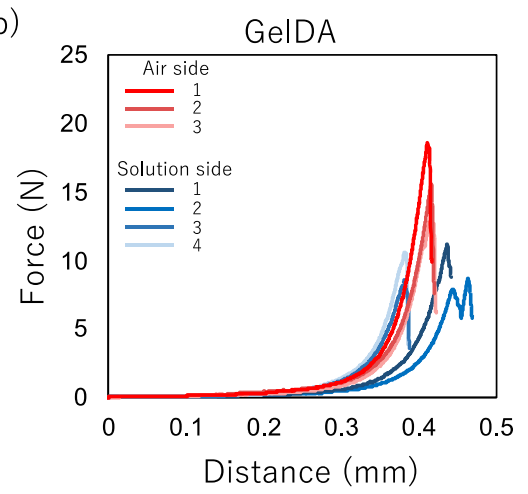

(c)

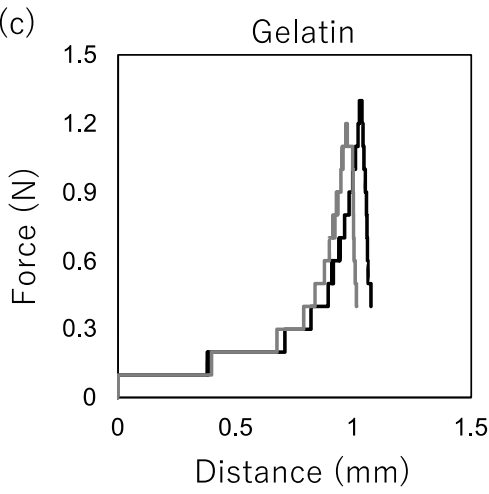

Figure S12. (a) The indentation test for the wet films. (b) Force curves of wet GelDA

films (red lines: air side of GelDA, $n=3$, blue lines: solution side of GelDA, $n=4$ ). (c) Force curves of wet gelatin films, $\mathrm{n}=2$. 